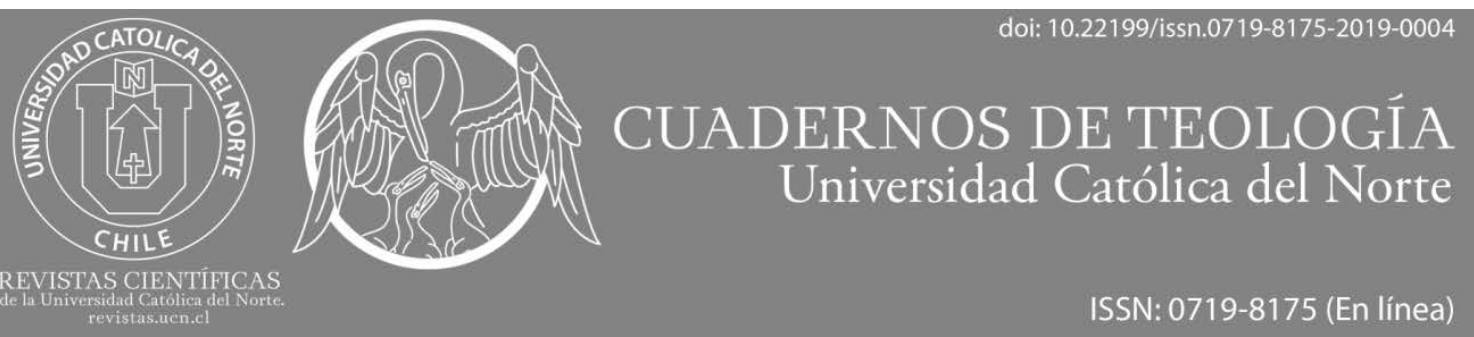

\title{
Más acá de la divinidad absoluta: liberación de las religiones y religiones para la liberación
}

Beyond the absolute divinity: liberation of religions and religions for liberation

\author{
Jairo Marcos* (iD) https://orcid.org/0000-0002-3738-1199 \\ * desplazados.org. Periodista, Mag. en Filosofía Teoríca y Practica, Doctorando Internacional en Filosofía. U. \\ Nacional de Educación a Distancia, España y U. Nacional Autónoma de México, México. \\ (a) jmarcos@desplazados.org \\ (cc) BY
}

\section{Resumen:}

Las víctimas posibilitan una liberación de las religiones y exigen unas consiguientes religiones para la liberación. Planteado desde las periferias (principalmente las abiertas por Gianni Vattimo, Enrique Dussel y Boaventura de Sousa Santos), este artículo reflexiona sobre la dimensión de ultimidad desde un enjambre pluriversal e interreligioso transformador, en el que Dios se vacía, se hace minúsculo, y las víctimas pasan a ser el criterio último de la religiosidad. Este descentramiento no niega automáticamente a lo otro infinito ni tampoco se arroja en brazos de la nada infinita, sino que posterga dicha cuestión para priorizar la religiosidad desde nos-otras, las víctimas. Lo religioso queda despojado de la Verdad mayúscula, tal y como sucede con otras esferas existenciales de la humanidad. Se dibuja así un pluriverso religioso tejido más acá de la Divinidad absoluta, pero al mismo tiempo más allá de un ingenuo diálogo mundial entre religiones.

Palabras Clave: Religión; Liberación; Víctimas; Vaciamiento; Dios.

\section{Abstract:}

Victims enable a liberation of religions and demand consequent religions for liberation. Raised from the peripheries (mainly those opened by Gianni Vattimo, Enrique Dussel and Boaventura de Sousa Santos), this article considers the last dimension from a multicultural and interreligious transformer schedule, in which God empties, becoming minor, and victims become the ultimate criterion of religiosity. This decentralization does not automatically deny the other infinite nor does it adopt the infinite nothingness, but rather it postpones that question to prioritize religiosity from the we-others, the victims. The religious is dispelled from the capital Truth, as it happens with other existential spheres of humanity. By this way, it appears a religious pluriverse woven beyond absolute Divinity, but at the same time beyond a naive worldwide dialogue between religions.

Keywords: Religion; Liberation; Victims; Emptying; God. 


\section{Introducción}

La humanidad no se reduce al encuentro cada vez más vertiginoso de la espacialidad y de la temporalidad eurocéntricos. La existencia humana desborda las dimensiones espacio-temporales, allí donde las preguntas giran no solo en torno a los otros existenciales, sino también en torno a lo otro infinito o a la nada infinita. Porque tener humanidad supone una (con)vivencia intersubjetiva entre los seres vivos y el ecosistema, con el otro plural como a priori ético transformador $y$, desde la finita condición humana, también implica la impotencia de afirmar o negar rotundamente la (im)posibilidad de lo infinito. "La razón moderna lo cuestionaba y criticaba todo a partir de sí misma. (...) Hoy, en cambio, hemos tomado conciencia de que la misma razón cuestionante es abarcada y cuestionada por la pregunta metafísica que lo cuestiona todo: '¿por qué se da el ser y no más bien la nada?"' (Scannone, 2005, p. 23).

Las otredades transformadoras pluridimensionales reflexionan esa pregunta desde un horizonte liminar, pues es precisamente en la geografía abrupta de los márgenes donde puede habitar(se) el otro o la nada infinitos. Es lo que Scannone $(2005$, p. 231) refleja a la hora de aprehender al ser humano "capaz de trascender el límite con su comprensión y su libertad, sin propiamente traspasarlo en el sentido etimológico de la palabra, a saber, sin atravesar su umbral, sino viviendo y comprendiendo así más profundamente la finitud humana". Aun desde corporalidades espaciales y temporales, desde la aceptación de la finitud en cuanto encarnación pluridimensional concreta, la humanidad se abre así a la posibilidad de otra existencia o de la nada infinitas.
Este desbordamiento que la finitud puede realizar de la infinitud es lo que sitúa al ser humano ante el misterio de transgredir los límites, hacia una transontología de lo otro infinito o transontología de la nada. El planteamiento de lo infinitamente otro, o de lo infinitamente nada, es factible únicamente tras la superación de la ontología fundamental, pues "un pensamiento de totalidad y mismidad tiende o bien a diluir la alteridad (...) del hombre y la consistencia y autonomía del mundo (...), o bien a negar la trascendencia" (Scannone, 2005, pp. 121 y122). Se trata de "la dimensión de ultimidad del hombre" (Fraijó Nieto, 2005, p. 747) o, dicho en términos más simples, de la religiosidad o de lo religioso en general $y$, más en concreto, del Dios de las religiones proféticas (judaísmo, cristianismo, islam), que regresa si es que alguna vez se hubo marchado: "La religión y las religiones son de hecho dimensión constante de la cultura y las culturas en la historia. Son un fenómeno humano -histórico, cultural, social y psicológico - tanto para el creyente como para el no creyente" (Scannone, 2005, p. 163).

La(s) Modernidad(es), ciertamente, recluyó(eron) la religiosidad como un conjunto de creencias que ya no eran necesarias ni aceptables ante las explicaciones del mundo que proveía la Ciencia y dado el orden que promovía la Técnica, que configuraban un mundo autorregulado: "Con la llegada de la Modernidad, (...) terminaría siendo posible la teología de la muerte de Dios. La separación entre Dios y el mundo (...) tuvo como consecuencia un 'Dios sin mundo' y un 'mundo sin Dios'. Había sonado la hora del ateísmo" (Fraijó Nieto, 2006, pp. 156-157). La condena a Dios se impuso en el Centro y, bajo el manto colonial, se extendió de forma par- 
ticularmente sangrienta en las periferias: "Europa (...) se opondrá a las culturas periféricas, y en primer lugar a sus religiones, por ser expresión de brujerías, magia, hechicerías, barbarie, salvajismo, primitivismo, errores, posiciones no ilustradas, fanáticas, etc. La negación de todas las culturas periféricas se recubrirá bajo el argumento secularista de que la religión es expresión de irracionalidad y subdesarrollo, propio de los pueblos no-europeos" (Dussel Ambrosini, 2001, p. 417).

Pero la confirmación nietzscheana de la muerte de Dios (Gott ist tot) (Nietzsche, 2003) y la proclama heideggeriana del final de la Metafísica (Heidegger, 1994) generan un efecto inesperado, al "liberar el campo para una renovada posibilidad de la experiencia religiosa" (Vattimo, 2003, p. 26). Desde un interés compartido por alumbrar las incógnitas que acechan a la humanidad', la proclamada autarquía autosuficiente del mundo científico técnico arrincona a Dios como dimensión existencial innecesaria. Lejos de condenar al ser humano a un mundo sin preguntas abre el más allá infinito, sea este lo otro o la nada, se genera la posibilidad filosóficoexistencial de reflexionar y de intuir a dios en minúscula, de balbucearle de otro modo, de pensar en una deidad no absoluta, en una religiosidad debilitada, transmoderna incluso.

El planteamiento de una deidad omnipotente queda anulado como oxímoron precisamente desde nosotras, las víctimas, vidas existenciales. No puede hablarse de un Dios absoluto con Ayacu-

\footnotetext{
1 "Los orígenes de Dios (...) están en los procesos naturales a través de los cuales rezamos a Dios para protegernos de las fuerzas de la naturaleza. (...) La ciencia y la tecnología se desarrollaron también de este modo. $Y,(.$.$) a partir de cierto momento, Dios$ dejó de ser una necesidad" (Vattimo y Caputo, 2010, pp. 137 y138).
}

cho, con Auschwitz, con Hiroshima y Nagasaki, con Guantánamo, con el mar de Alborán, con la cronificación de las hambrunas. Pero las víctimas no niegan a Dios definitivamente, sino que obligan a replantear y transformar las preguntas (en este artículo, filosóficas concretamente, desde la filosofía de la religión²) por lo otro infinito, aun contemplado como nada infinita: "El planteo desde las víctimas de la injusticia hace caer en la cuenta de la libre vulnerabilidad, pasividad y pasión de Dios" (Scannone, 2005, p. 122). La religiosidad regresa transformada:

\begin{abstract}
"En el inicio del siglo XXI, la religión y la teología están de vuelta. No es tan cierto que Dios esté también de vuelta, por lo menos, no el Dios (...) como garante último. (...) Dios se revela en el sufrimiento humano injusto, en las experiencias de vida de todas las víctimas de dominación, opresión o discriminación y en las luchas de resistencia que promueven. Como consecuencia, prestar testimonio a este Dios significa denunciar este sufrimiento y luchar contra él. (...) Aquí reside la posibilidad de vincular el retorno de Dios a un humanismo insurgente, trans-moderno, concreto (De Sousa Santos, 2014, p. 104).
\end{abstract}

Desde su trascendencia ética y como alteridades transformadoras, las víctimas obligan a revisar y reformular los vínculos entre lo religioso y la injusticia histórica, los límites en cuanto límites de

\footnotetext{
2 El nacimiento de esta relación no-subordinada entre lo filosófico y lo religioso, que todavía hoy configura sus contenidos y metodologías, se remonta a finales del siglo XVIII y "fue posible (...) porque muchos absolutos saltaron hechos añicos" (Fraijó Nieto, 1994, p. 28).
} 
la existencia humana. "La primera dificultad es que (...) ya no podemos buscar soluciones morales fijas en el Cielo o en el Tao, y tampoco deducirlas de la Biblia o de cualquier otro libro sagrado" (Küng, 2006, p. 69). Y es que, más acá del Dios absoluto en quien excusar el sufrimiento y las injusticias presentes en aras a una salvación por venir, la religiosidad en el 'buen senti$d o^{\prime}$ horkheimeriano coincide con la transformación realizada desde, con y por nosotras, las víctimas, en "el inextinguible impulso, sostenido contra la realidad, de que esta debe cambiar, que se rompa la maldición y se abra paso la justicia" (Horkheimer, 2000, p. 226).

Excluir la dimensión existencialreligiosa sería dejar fuera, como frecuentemente hacen tanto el materialismo capitalista como el marxista ateo, la dimensión liminar o última de la humanidad, con especial perjuicio para las víctimas. "Para que sea auténticamente humana, la liberación debe abrirse a otras dimensiones (...) y tratar de ser integral" (Boff, 1981, p. 122); esta dimensión existencial de la humanidad es la que refleja la religión en cuanto vínculo que re-liga a los seres humanos (y al ecosistema) con lo otro infinito o con la nada infinita. Se trata de una dimensión más allá de lo racional y más acá de lo mítico, de una dimensión exsistencial humana de contornos y posiciones limítrofes: "Las religiones se mueven entre la sabiduría mítica y la búsqueda racional. (...) No pueden renunciar a los mitos, que son relatos portadores de significados múltiples y cauces de expresión y comunicación de lo que no puede transmitirse por la vía lógica" (Tamayo Acosta, 2011, pp. 43 y 44).
Por mucho que avancen la crisis de la institucionalidad religiosa ${ }^{3}$ y la secularización ${ }^{4}$, lo religioso permanece muy vigente en las sociedades contemporáneas: "Si durante muchos decenios (...) las religiones han aparecido, de acuerdo con la idea ilustrada y positivista, como formas de experiencia 'residual', destinadas a agotarse a medida que se imponía la forma de vida 'moderna', hoy aparecen nuevamente como posibles guías para el futuro" (Vattimo, 1996, pp. 21 y 22). Innumerables veces se ha dado por muertas a las religiones ${ }^{5}$, nunca con tanta virulencia como durante el siglo XX, pero una y otra vez han resistido: "Los pronósticos no parecen haberse cumplido. A partir de 1970 se produjo un fenómeno conocido como 'sorpresa de lo divino'. (...) De entonces hasta ahora, las religiones (...) han resurgido como fuerza social, han cobrado relevancia política, han recuperado el espacio público perdido (...), reclaman el liderazgo ético y pretenden afirmarse como parte fundamental de la identidad cultural" (Tamayo Acosta, 2011, p. 25) ${ }^{6}$. Ejemplos de este resurgir de la

\footnotetext{
3 "La decadencia de la religión como institución y la vivencia de la misma de manera desinstitucionalizada es (...) una de las principales características del nuevo clima religioso" (Tamayo Acosta, 2004, p. 59). 4 "La secularización no ha logrado eliminar la religiosidad popular que, aunque menguada, persiste y sigue viva. (...) A ello cabe sumar nuevas formas de religiosidad grupal comprometida. (...) La religión aparece de múltiples formas" (Tamayo Acosta, 2004, p. 60).

${ }^{5}$ Religiones y no religión, pues no existe una sola creencia sino varias y muy diversas. Otra cuestión es que pueda hablarse de lo religioso o de la religiosidad como dimensión ex-sistencial última o liminar de la humanidad. Además, en el caso de la comunidad creyente puede hablarse de la teología como "la conciencia de que este mundo es un fenómeno, que no es la verdad absoluta, que no es lo último" (Horkheimer, 2000, p. 169).

${ }^{6}$ Según las últimas cifras que ofrece el Centro de Investigaciones Pew, el 83,6 por ciento de la población mundial se identifica con alguna confesión en concreto y el 16,4 por ciento restante incluye a personas ateas y agnósticas, pero también a quienes confiesan creencias espirituales o religiosas no
} 
religiosidad son los 'nuevos movimientos religiosos', que incluyen una amplia gama de formas y creencias, incluyendo las sectas; las espiritualidades feministas, que denuncian las mediaciones y representaciones patriarcales acerca de lo divino ${ }^{7}$; la religión de la diosa, que recupera deidades femeninas; el ecofeminismo, que se basa en la creencia en una interdependencia ecosistémica generada en torno a un Cuerpo Mayor; e incluso la privatización de las religiones, que comercializa lo religioso como un sentimiento individual listo para ser consumido.

Pero, sobre todo, el planteamiento de lo religioso como dimensión exsistencial humana es necesario porque del anhelo por lo infinitamente otro emana una letanía de cuestiones antropológicas y últimas compartidas tanto por creyentes y no creyentes como por ateos, y principalmente por las víctimas ${ }^{8}$, sobre quienes revolotea una especie de resistencia última ante lo Mismo, a modo de pregunta dirigida más allá de la racionalidad y de lo telúrico: "La convicción común a creyentes en Dios y ateos de que el mundo actual con todas sus injusticias no está en orden mantiene vivo en la humanidad el anhelo por alguien enteramente otro: por una realidad última, diferente de este mundo aparente, constatable y contradictorio en sí mismo,

vinculadas a ninguna fe en particular (Pew Research Center, 2019).

7 "Son esencialmente los seres humanos masculinos los principales responsables de la imagen de Dios transmitida en la sociedad. Siendo así, (...) estamos conociendo en cierta forma a esos mismos hombres de los cuales Dios aparece como imagen. (...) Consecuentemente, conocemos a aquellos que hablan de Dios y casi desconocemos a aquellos/as que están callados/as" (Gebara, 2000, pp. 55-56).

8 "Mayoritariamente, los pobres se agarran a 10 religioso porque en muchísimas ocasiones no tienen ninguna otra realidad a la que agarrarse" (Sobrino, 1988, p. 3). como quiera que dicha realidad se entienda" (Küng, 1979, pp. 763-764).

Proyectado en una dimensión existencial liminar, este anhelo de otra realidad distinta a la Mismidad coincide con el proceso transformador de debilitamiento y liberación sureadores, sin la exigencia de abrazar lo infinitamente otro ni tampoco de conformarse con su ausencia infinita. Otredad o nada infinitas, "Io esencial es (...) el anhelo de que la realidad del mundo con todo su horror no sea lo último que une y relaciona a todos los hombres que no pueden o no quieren resignarse a la injusticia de este mundo" (Horkheimer, 2000 , p. 136). No hay por tanto necesidad de abordar lo religioso desde una perspectiva creyente 0 atea, pues la transformación de lo religioso no pasa por la apología ciega ni por la obsesión aniquiladora del dogma ultraterreno ${ }^{9}$. La transformación de la dimensión liminar ex-sistencial del ser humano no agota la cuestión de la posibilidad o imposibilidad de Dios; de hecho, "el anhelo de que la injusticia no sea la última palabra es obviamente compatible con la sospecha de que 'quizás el mal sea inerradicable en este mundo'; $y$ tanto el uno como la otra lo serían, a su vez, con la desazonante posibilidad de que -ni para bien ni para mal- haya una última palabra" (Muguerza Carpintier, 2006, p. 457).

\footnotetext{
9 "Resulta estéril y contraproducente combatir frontalmente a las religiones de manera indiscriminada desde una actitud militante antirreligiosa. Dicha actitud resulta tan caduca como algunas de las manifestaciones que se pretenden combatir y lleva de manera directa a actitudes de autodefensa que desembocan con frecuencia en fundamentalismo, fanatismo y sectarismo. Pero tampoco se puede caer en una fácil apologética que idealice las religiones y las presente con todos los bienes sin ningún tipo de mal" (Tamayo Acosta, 2001, pp. 29-30).
} 


\section{Hacia una transformación de la dimensión religiosa}

Esta transformación de la dimensión religioso-existencial no es en todo caso viable desde un paradigma abstracto y ahistórico. No es el planteamiento de la religiosidad como "magnitud eterna y ahistórica, sino como expresión de una realidad que es transhistórica y trans-social" (Küng, 1998, p. 19). El descarte de una Divinidad absoluta en cuanto tal rescata de forma paralela los matices socio-políticos de la dimensión religiosa: "La fe vivida en comunidad (Iglesia) participa de lo político porque posee y transmite su visión del mundo y del hombre y, a partir de ella, entra en una relación de crítica, de rechazo o de colaboración con otras ideologías políticas" (Boff, 1981 , pp. 87 y 88$)^{10}$. La teología política, semilla de las teologías de la liberación, reivindican esta raigambre política de la fe, al partir del "supuesto de que el saber y el comportamiento religiosos tienen implicaciones políticas y sociales" (Metz, 1979, p. 161).

Precisamente como fenómeno existencial socio-político, las religiones han demostrado ser capaces de lo mejor y también de lo peor. El fundamentalismo religioso y el rigorismo moral, el dogmatismo y el integrismo han sembrado fanatismo y han recogido terror en innumerables ocasiones (limpiezas étnicoreligiosas, discriminaciones de género, procesos inquisitoriales, etc.), enfangando debates en torno a cuestiones como el aborto, la eutanasia, la sexualidad y el modelo de familia. Izando la bandera del Dios propio ${ }^{11}$, su capacidad destructiva ha

\footnotetext{
${ }^{10}$ La conciencia política de la religiosidad es manifiesta, por ejemplo, en la teología de la liberación. 11 "Si dios está con nosotros, con nuestra religión, nación, confesión o partido, entonces todo está
}

generado guerras y muerte por doquier, en algunos casos de forma directa (Irlanda del Norte, Yugoslavia, Filipinas, Palestina, Cachemira, Sri Lanka, etc.) y en otros, al menos como inspiración de fondo (los dos grandes conflictos bélicos). "Existen sobrados ejemplos de cómo las religiones pueden fomentar el odio y la enemistad e instigar y legitimar guerras. ¿Podría ser todo esto solo el múltiple preludio de una nueva gran tragedia de la humanidad?" (Küng, 1999, p. 126) ${ }^{12}$.

Pero la negativa es solo una de las caras de las religiones, que también han fomentado y respaldan valores constructivos, como durante el movimiento por los derechos ciudadanos de Estados Unidos, en el apartheid de Sudáfrica y, más recientemente, en su labor de presión para la aprobación de los (limitados) objetivos de desarrollo sostenible de la Agenda 2030 (Tatay Nieto y Devitt, 2017). Tampoco faltan los modelos vida que ofrecen Confucio, Buda, Jesús de Nazaret, Mahoma, Francisco de Asís, Gandhi, Luther King, Bonhoeffer, Romero, Ellacuría y Teresa de Calcuta, entre otros religiosos y religiosas. Y son también numerosas las veces en las que lo religioso ha jugado un papel clave en la defensa de la población empobrecida, como sucede con las teologías de la liberación latinoamericanas. Esta cara positiva de la religiosidad es la que recoge el teólogo Küng (2006, p. 98) en su Proyecto de una ética mundial: "Todas las religiones del mundo han de reconocer la responsabilidad que les compete con respecto a la paz mundial. No puede haber paz

permitido con los contrarios, pues deben venir necesariamente del diablo. En nombre de Dios será preciso agredir, incendiar, destruir y matar" (Küng, 2006, p. 97).

${ }_{12}$ Precisamente el planteamiento que pone sobre la mesa Huntington (2001) es El choque de civilizaciones provocado por las religiones, principalmente, por el cristianismo y el islam. 
entre las naciones sin paz entre las religiones 0 , dicho más brevemente, imposible la paz mundial sin la paz religiosa"13.

Precisamente por las diferentes expresiones de las religiones, es necesario repensar lo religioso desde nos-otras, las víctimas. No es posible sostener a un Dios absoluto ni una estructura metafísica como fundamento último e inaccesible pero, paradójicamente por ello, es posible creer de otro modo. A través de Nietzsche y Heidegger, la aproximación debolista de Vattimo alumbra la religiosidad después de la muerte del Dios absoluto tal cual. Su propuesta del "vaciamiento" de Dios (en su caso, cristiano), a través de la kenosis (del griego $\kappa \varepsilon ́ v \omega \sigma \iota \zeta$, vaciamiento) constata el retorno de lo religioso de otra manera, mediante el regreso de la religiosidad débil, humilde, hermenéutica y no sacrificial, aplicada a la solidaridad para nihilizar lo impositivo fundamentalista de la Totalidad sin caer en la lógica relativista. Dios deja de Ser el fundamento inmóvil de la historia; su Verdad es sustituida por la caritas, entendida esta como la verdad que (se) habita en el amor al otro. Una invitación a balbucear a dios en minúscula.

La hermenéutica debolista de Vattimo encarna a dios, lo vacía para poder volver a creer en él, lo debilita para así abrazar su fuerza transformadora como última dimensión ex-sistencial. Al decir a dios de otro modo, su realidad deja de ser atemporal, independiente y absoluta. El habitar de dios solo es posible desde la ex-sistencia situada, concreta, tanto personal como colectiva, liminar de los seres

\footnotetext{
${ }^{13}$ La paz civilizacional de Küng queda subsumida como una propuesta encomiable pero no lo suficientemente transformadora desde la perspectiva de las víctimas, para quienes dicha paz universal corre el riesgo de seguir encerrando un exceso de injusticias y un defecto de transformaciones.
}

humanos y, con especial énfasis, desde los cuerpos de las víctimas: "El Infinito habita entre nosotros éticamente, a través de su huella impresa en el rostro del otro. Des decir, a través de la interpelación incondicionada del otro y de los otros. (...) Pero también habita numinosamente a través de lo simbólico de la tierra, fuente materna de vida. (...) Son dos modos distintos, complementarios e interrelacionados de habitar o estar presente lo divino en nosotros y entre nosotros" (Sannone, 2005, pp. 264265). La espiritualidad del ecofeminismo refleja en buena medida este giro transformador:

\begin{abstract}
"Nuestra experiencia ya no nos permite captar este misterio como una realidad totalmente otra y distinta de nosotros/as, como si hubiese un momento de ruptura o discontinuidad total entre nosotros/as y ese/a Otro/a. En el fondo, lo poco que captamos de ese misterio lo logramos a partir de nuestros límites, de nuestra corporeidad culturalmente situada. (...) Si este misterio está en nosotros/as y más allá de nosotros/as, ya no lo sentimos como todopoderoso, como señor, como juez último, ni siquiera como padre creador" (Gebara, 2000 , pp. 134 y 135 ).
\end{abstract}

La religiosidad aparece como dimensión de ultimidad (Fraijó Nieto, 2005) ex-sistencial de refugio, esperanza y liberación ante las injusticias sufridas por las vidas que también merecen ser vividas. La religiosidad trasciende, habitándola, la ex-sistencia humana: re-liga la pluridimensionalidad humana a otra dimensión, a una dimensión última, limítrofe y, como tal, no desconectada de las diferen- 
tes esferas de la realidad. Sea lo infinitamente otro o sea la nada infinita, se descubre una dimensión transformadora para las víctimas, una dimensión ex-sistencial de sentido, de responsabilidad, de esperanza, de resistencia y de liberación que justifica precisamente el 'anhelo de lo totalmente otro' (ver Horkheimer, 2000). Lo religioso (se) habita así de otro modo: "Dios más allá de las religiones y Dios en la religión, es decir, en la ligazón de todo con todo, de todas con todos. (...) Dios no con una voluntad, sino con voluntades. Dios no con un proyecto, sino con muchos. Dios no con un rostro, sino con miles. Dios no con una voz, sino con mil voces afinadas, desafinadas, sofocadas, desatinadas, desesperadas, consoladas, tiernas, apasionadas..." (Gebara, 2000, p. 144).

El riesgo de que la esperanza en lo ultraterreno se convierta en un narcótico tranquilizante es evidente pero, transformadas la espacialidad y la temporalidad, la liberación de lo religioso no tiene por qué encadenarse a un futuro mesiánico por-venir, sino a los cuerpos dolientes de nos-otras, las víctimas, en cada exsistencia concreta. Esta idea de religión ex-sistencial hace a los seres humanos conscientes de su posición interdependiente en el cosmos y de su dignidad. La dimensión liminar de la humanidad, sea esta concebida como lo otro infinito o como la nada infinita, conjuga así el debilitamiento y la liberación sureadores, con las víctimas como instancia decisiva.

\section{Transformación de la dimen- sión religiosa}

La profundidad transformadora de la última esfera de existencia pasa por reubicar lo religioso en torno a las víctimas, descentrándolo más acá de la Divini- dad absoluta, con la necesaria humanización de la religiosidad a la que conducen las víctimas. La clarividencia entre lo otro infinito o la nada infinita puede esperar pues, más que una respuesta definitiva acerca de la (im)posibilidad de la infinitud, las periferias posibilitan una liberación de las religiones y exigen unas consiguientes religiones para la liberación. Por eso tampoco es cuestión de confiar la salvación de la deshumanización del mundo a un credo concreto, sino de plantear la dimensión de ultimidad desde un enjambre pluriversal e interreligioso transformador que incluya las posturas agnósticas y ateas.

Dios se vacía, se hace minúsculo, y las víctimas pasan a ser el criterio último de la religiosidad. Este descentramiento no niega automáticamente a lo otro infinito ni tampoco se arroja en brazos de la nada infinita, sino que posterga dicha cuestión para priorizar la religiosidad desde nos-otras, las víctimas. Las consecuencias de la kenosis (del griego $\kappa \varepsilon ́ v \omega \sigma \iota \varsigma$, vaciamiento) vattimiana son radicales: "Significa que la salvación consiste ante todo en romper la identidad entre Dios y el orden del mundo real. (...) Un Dios 'diferente' del ser metafísico ya no puede ser el Dios de la verdad definitiva y absoluta que no admite diversidad doctrinal alguna. Por eso puede Ilamársele un Dios 'relativista'. Un Dios 'débil'"' (Vattimo, 2010, p. 71).

Ha de admitirse la extrema dificultad de concebir a lo otro infinito o a la nada infinita y al mismo tiempo concebirlos como un otro o una nada limitado/a, debilitado/a o vaciado/a. Para comprenderlo mejor, la dimensión religiosa puede echar mano de las ciencias ${ }^{14}$, acostum-

\footnotetext{
${ }^{14}$ Esta remisión a la ciencia en el campo de lo
} religioso no debería extrañar. Las religiones han de 
bradas a lidiar con estas dos magnitudes; de hecho, el infinito y el cero o la nada están íntimamente ligados en las matemáticas y ambos parecen oponerse a su división: ¿acaso es posible dividir el 0 , por ejemplo, en tres partes? y ¿cuál es la mitad del infinito? La teoría de los conjuntos de Cantor (2006) permite que tanto el infinito como la nada sean manipulables; por extraño que pueda parecer, las matemáticas admiten desde entonces la comparación entre infinitos (o entre nadas) y que unos infinitos (o nadas) resulten mayores o menores que otros/as sin perder su infinitud ${ }^{15}$. Del mismo modo, el vaciamiento de dios no cuestiona su infinitud, pero sí rebaja, debilita y a la postre anula su condición de absoluto.

Lo religioso queda despojado de la Verdad mayúscula, tal y como sucede con otras esferas existenciales de la humanidad. La ontología hermenéutica radical y nihilista de Vattimo convierte la Verdad en algo innecesario, puede que incluso inconveniente para el ser humano; y sin embargo las víctimas siguen ahí. Por eso la parábola hermenéutica debolista que no destruye (Überwindung) la Verdad, sino que la distorsiona rememorativamente (Verwindung). Sobre la mesa aparecían dos conceptos veritativos: la Ver-

abrirse no solamente a un encuentro interreligioso, analizado a continuación, sino también a las diversas racionalidades, para lo cual "deberán renunciar a su pretensión de verdad absoluta, asumiendo humildemente sus límites epistemológicos, aceptando las conclusiones de la mejor ciencia disponible y delimitando el ámbito de su autoridad" (Tatay Nieto, 2019, p. 21).

${ }^{15}$ Por ejemplo, el conjunto de los números naturales $(1,2,3,4,5,6,7,8,9 \ldots n)$ es infinito $y$, al mismo tiempo, mayor que el conjunto, también infinito, de los números pares $(2,4,6,8,10,12,14,16,18 \ldots$ n). Denostado durante años por la comunidad científica, hoy las ideas de Cantor (2006) aportan un sostén clave a las matemáticas contemporáneas. Una explicación más detallada a la teoría de conjuntos excede los límites del presente artículo. dad como adecuación objetiva y excluyente, y la verdad más allá de la mera objetividad, verdad global encarnada, la verdad de las víctimas. Al no tratarse ya de la búsqueda de la Verdad mayúscula, las víctimas son quienes habitan corporalmente las verdades, siempre de forma abierta dados unos cuerpos finitos y dolientes. "Son portadores de verdad. Por 10 que son, ofrecen luz al mundo de abundancia para que este vea su verdad y así pueda encaminarse a toda verdad" (Sobrino, 2007 , p. 87). No es que las víctimas sean verdad, sino que llevan consigo las verdades, también en su dimensión existencial liminar.

Sin Verdad que revelar, ningún dios es absoluto y tampoco existe libro sagrado alguno que detente el privilegio de expresar la Última Palabra. De ahí también que, en la esfera de la religiosidad, haya que hablar de 'religiones' y no de 'religión', ni siquiera como el perfecto resultado final de un diálogo interreligioso: "La idea de una religión universal es una secuela del período colonialista de la historia humana. (...) Una religión única universal y uniforme representaría un empobrecimiento de la rica experiencia religiosa de la humanidad" (Fraijó Nieto, 2005, p. 751). Teólogas como Gebara (2000, p. 120) adoptan de la biología y de la ecología el término 'biodiversidad', hablando de 'biodiversidad religiosa' como "la afirmación de que una sola visión de la realidad, una única construcción de sentido, no puede ser la detentadora de la verdad o la que más se acerca a ella. Significa que no hay solo una manera de afirmar el sentido de la vida, sino millares. Algunas se encuentran, otras entran en conflicto, otras se excluyen".

Pero corren malos tiempos para las posturas débiles y más si cabe en lo 
que a las tradiciones religiosas se refiere, principalmente las monoteístas (cristianismo, islam, sijismo, judaísmo, bahaísmo, zoroastrismo), que afianzan su credo en torno a una letanía de conceptos fuertes plasmados en los libros sagrados: 'Dios', 'Verdad', 'Dogma', 'Revelación', 'Fe'. Pero vaciado dios, lo categórico pierde su lugar, si es que alguna vez realmente lo tuvo en lo religioso, "tan misterioso, tan tremendo y fascinante, tan abierto e inseguro. (...) El mundo religioso es un noble entramado de preguntas, de barruntos, de inquietudes, de anhelos. $Y$ es altamente posible que todo lo humano, incluso los más dotados religiosamente, abandonen este mundo con una razonable duda sobre el destino final de tanta desazón" (Fraijó Nieto, 2007 , pp. 269 y 270 ).

En un camino tan incierto, otra religiosidad es posible más acá de la Divinidad absoluta. Se abren las ventanas hacia una liberación de las religiones, y hacia una teología más humana cuando se admite lo otro infinito, sin reducir por ello lo religioso a lo humano, sino recurriendo a ese desbordamiento que la finitud puede realizar de la infinitud, lo que sitúa al ser humano ante el misterio de transgredir los límites, sus propios límites. La transformación de lo religioso no subsume la religiosidad en lo humano, pero sí que la hace pivotar en torno a las víctimas: "No nos movemos (...) en un círculo vicioso, pero sí (...) en una relación de intercambio dialéctico: 1) ¡Verdadera humanidad es presupuesto de verdadera religión! Lo humano (...) es una exigencia mínima para toda religión (...). 2) ¡Una verdadera religión es culminación de una verdadera humanidad! La religión (...) es un presupuesto optimal para la realización de lo humano" (Küng, 1998, pp. 200 y 201).
En medio de tanta incertidumbre, se dibuja un pluriverso religioso tejido más acá de la Divinidad absoluta, pero al mismo tiempo más allá de ese diálogo mundial entre religiones de Küng (2006) que, priorizando la consecución de una ética mundial, corre el riesgo de olvidar las cicatrices de las víctimas y de minusvalorar las condiciones históricas de cada religión. A partir de las víctimas y con la mirada puesta no en revelar la Verdad, sino en la congregación de unas religiones para la liberación, "de lo que se trata (...) es de crear una teología interreligiosa de la liberación que asuma las tradiciones emancipatorias presentes en las distintas religiones y movimientos espirituales" (Tamayo Acosta, 2011, p. 137).

\section{Liberación de las religiones: las víctimas}

El punto nodal de lo religioso deja de ser el Dios absoluto y se encarna en los cuerpos de las víctimas: "La 'marginación' y la 'exclusión social' (...) son, a su vez, categorías teológicas que interpretan la realidad analizada a la luz de la experiencia liberadora de la fe, vivida en comunidad" (Tamayo Acosta, 2003, p. 395). La respuesta al interrogante religioso por la salvación está ineludiblemente en relación con las víctimas, no porque las víctimas garanticen la liberación, sino porque, sin ellas, lógicamente evitables pero empíricamente ineludibles, no hay liberación ni transformación posibles. Conjugado en un lenguaje religioso, la gracia y la salvación se reciben de y desde nos-otras, las víctimas: "En el mundo de los pobres se genera una lógica que permite ver la realidad de otra manera. (...) Permite ver que de los pobres puede venir salvación. Para los no-pobres es la experiencia de gracia. La opción por los pobres no versa ya solo sobre 
dar a ellos, sino sobre recibir de ellos" (Sobrino, 2007, p. 80) ${ }^{16}$.

Es en las víctimas donde el valor de la religiosidad no se mide por su acercamiento a la Verdad, sino por su alcance transformador; una transformación que puede ser compartida por varias tradiciones con pretensiones pluriversales no absolutistas: "No parece que se pueda reprochar a los miembros de una religión que, si están convencidos de la verdad de su religión, procuren que esta alcance a todos. (...) Con dos condiciones. (...) Primera: que (...) no degenere en pretensión de carácter absoluto. (...) Segunda (...): será legítima con tal de que no sea impuesta" (Fraijó Nieto, 2007, p. 264). Y es que, desde un punto de vista interno cada religión puede seguir revelando su verdad, siempre y cuando desde un punto de vista externo cada religión sea consciente de que dicha verdad no se posee, sino que la habitan temporalmente las víctimas. A través de dicho desdoblamiento consciente, hacia adentro y hacia afuera, las religiones vacían a su(s) dios(es), debilitan consecuentemente sus dogmas y se liberan ellas mismas de las ataduras a la Verdad. De fondo, se trata de la humanización hermenéutica $^{17}$ de lo otro infinito, lo que tiene consecuencias ya en el mismo discurso religioso, que abandona el lenguaje fáctico para abrazar lo simbólico y lo metafórico.

\footnotetext{
${ }^{16}$ Como se verá a continuación, la teología de la liberación latinoamericana surgió en torno a la categoría de 'pobre', que posteriormente será ampliada a la de 'víctima'.

17 "El horizonte hermenéutico constituye la clave de cualquier teología; intenta liberar al discurso religioso de todo resto de fundamentalismo, e implica el paso de la teología como mera exégesis de textos a una teología hermenéutica en busca de sentido. Sin la mediación hermenéutica, el discurso teológico deja de ser tal para convertirse en repetición de los textos del pasado, reproducción del discurso religioso oficial, legitimación de las instituciones religiosas y simple glosa de las declaraciones doctrinales surgidas de los respectivos magisterios jerárquicos" (Tamayo Acosta, 2011, p. 138).
}

Como expresiones existenciales socio-políticas, el potencial transformador de cada una de las religiones está relacionado con sus consecuencias (De Sousa Santos, $2005^{18}$ ) en las vidas que también merecen ser vividas. En este sentido, no todas las religiones son igualmente transformadoras, pero todas pueden aproximarse a ciertos grados de liberación. De hecho, sobre el papel, las tradiciones religiosas mayoritarias enarbolan lo que Küng llama "Regla de oro de la humanidad": no hagas a los demás lo que no desees para ti mismo ${ }^{19}$, que convertido a un lenguaje periférico resulta en la prohibición de que la Razón excluyente del YoNosotros use al otro plural despojándole de su dignidad humana. En la dimensión existencial liminar, para afirmar que una religión es transformadora, "hay que analizar (...) si de hecho se traduce en ánimo y no en obstáculo a movimientos liberadores concretos, si tiene capacidad de integrarse en ellos y si tiene capacidad de aportar lo suyo religioso específico para potenciarlos y salvarlos" (Sobrino, 1998, p. 10) ${ }^{20}$.

Cualquier encuentro interreligioso está condenado al fracaso si no se tiene

\footnotetext{
${ }^{18}$ Las consecuencias son lo primero que sufren las víctimas.

${ }^{19}$ Küng (1999, p. 111) recoge la formulación de esta regla de oro en varias tradiciones éticas y religiosas: el confucianismo (Confucio: "Lo que tú mismo no quieres, no lo hagas a otros hombres"); el judaísmo (Hillel: "No hagas a otros lo que no quieres que ellos te hagan a ti"); el cristianismo (Jesús de Nazaret: "Todo cuanto queráis que os hagan los hombres, hacédselo también vosotros"); el islam (alNawawi's: "Ninguno de vosotros será un creyente mientras no desee para su hermano lo que desea para sí mismo"; el jainismo (Sudharmasvami: "Como indiferente a todas las cosas mundanas debiera comportarse el hombre, y tratar a todas las criaturas del mundo como él mismo quisiera ser tratado"); el budismo (Samyutta Nikaya: "Una situación que no es agradable o conveniente para mí, tampoco lo será para él, y una situación que no es agradable o conveniente para mí, ¿cómo se la voy a exigir a otro?"); y el hinduismo (Mahabharata: "No debería uno comportarse con otros de un modo que es desagradable para uno mismo").

20 Sobrino identifica varios elementos de esta especificidad religiosa: misericordia, diálogo, perdón, desfanatización y mística de la paz.
} 
en cuenta esta aproximación comprometida con las víctimas, con las vidas periféricas anegadas por la Totalidad: sures de geografía diversa, mujeres y vidas sobrantes. Desde sus alteridades u otredades transformadoras, el otro plural y, en concreto, las víctimas son la instancia decisiva (mas no excluyente) también de la religiosidad $^{21}$; lo son sin despojarse de su condición finita e interdependiente, lo que conduce o debería conducir a manifestaciones religiosas de "afirmaciones más existenciales, más humildes, más aproximativas y dialogales" (Gebara, 2000, p. 76).

Desde un paradigma espiritual biodiverso, tanto las expresiones como las vías de salvación de lo sagrado fluyen hacia un encuentro interreligioso que, sin ser doctrinario, no se conforme con el mero sincretismo ${ }^{22}$ y vaya más allá del tolerante diálogo ecuménico que propone Küng. Para que dicho encuentro interreligioso sea transformador, cada religión debe abrirse a las revelaciones de los otros credos $^{23}$, pero en una curvatura que tam-

\footnotetext{
21 "Los no-pobres pueden ser necesarios para potenciar la salvación que viene de los pobres. Pueden convertirse en figuras de tipo profético para que los pobres puedan recuperar y mantener la confianza en sí mismos, desarrollar prácticas y contagiar esperanza. (...) Esas figuras pueden venir de los mismos pobres, pero también de los no-pobres. El arzobispo Romero, el rector Ellacuría no eran del mundo de los pobres. Pero al abajarse, ellos mismos recibieron la salvación, y los pobres quedaron potenciados en cuanto salvadores" (Sobrino, 2007, pp. 96 y 97).

22 "Lo que se ha dado en Ilamar "la paella de las religiones', en la que cada cual se podría servir a su gusto, (...) no haría más que reforzar la tendencia egocéntrica de consumo fomentada por la sociedad. (...) Tomar elementos sueltos de las diferentes religiones es delicado, porque supone desintegrarlos de su contexto" (Melloni Ribas, 2000, p. 4). El título de su artículo hace referencia a la parábola oriental en la que un elefante (símil de lo religioso) es rodeado por cinco ciegos (que representan a las diferentes religiones), cada uno tocando una parte del animal (las patas, la cola, el vientre, la trompa y los colmillos) y ninguno de ellos adivinando la identidad del elefante. Pese a la tentación de cada ciego de pensar que tienen la visión global, la parábola señala el carácter analógico y condicionado del conocimiento religioso.

${ }^{23}$ Melloni Ribas(2000) resume las aportaciones más sustanciales de cada religión: el ser innom-
}

poco suprima las propias creencias cuando son planteadas y asumidas de forma autocrítica hacia dentro y crítica hacia afuera. Despedidas la Metafísica y la Verdad con mayúsculas, el diálogo entre religiones no es un fin en sí mismo ni tampoco algo absoluto. De hecho, es otra fase más del proceso de liberación de las religiones ${ }^{24}$. La comunicación interreligiosa "no puede quedarse en un diálogo entre caballeros que disfrutan en una conversación sobre todo lo divino y lo humano. (...) Ha de tener un horizonte, un punto de partida y una meta. El horizonte son las víctimas del sistema. (...) El punto de partida es la experiencia humana y religiosa. (...) El punto de llegada será la construcción de una sociedad multicultural, multiétnica, tolerante y justa, sororal y fraterna" (Tamayo Acosta, 2004, pp. 305 y 306).

\section{Religiones para la liberación}

Entre la fe en el Dios propio y el debilitamiento, entre la identidad de una comunidad de creyentes y la pluriversidad, entre la firmeza de los dogmas de un credo y la apertura, las víctimas son la instancia decisiva que alumbra, una vez más, el proceso de cualquier encuentro interreligioso que se pretenda transformar. De la liberación de las religiones a las religiones para la liberación. Las víctimas

\footnotetext{
brable y personal del judaísmo, el dios más allá de toda imagen del islam, el dios encarnado en comunión del cristianismo, la múltiple manifestación de la divinidad del hinduismo, la disolución del yo del budismo, la noción del 'vacío' del taoísmo, el respeto por la memoria y el orden social del confucianismo, la percepción del alma de los seres del animismo y el valor de la madre naturaleza de las religiones amerindias, además de la aceptación de la finitud de las posiciones no-creyentes y del camino de humildad del agnosticismo.

${ }^{24}$ El carácter procesual de la transformación religiosa queda reflejado en voces como la de Panikkar (1965), quien observa hasta siete pasos: coexistencia, tolerancia, dia-logo (intercambio de logoi, palabras), comprensión mutua, comunicación (un diálogo dialógico que traspasa al mero dia-logo al ir más allá de la confrontación), enriquecimiento mutuo y, finalmente, comunión.
} 
son el horizonte sobre el que debe moverse una ecología de las religiones que parta de una igualdad inicial (relaciones simétricas entre las religiones, hasta que sean verificadas sus consecuencias transformadoras) y que esté atravesada por una responsabilidad glocal con dichas víctimas.

Aun dificultados por "el desconocimiento mutuo que se tienen las religiones entre sí, su falta de sentido autocrítico y la tendencia a la descalificación de unas con otras" (Tamayo Acosta, 2004, p. 20), las tradiciones religiosas muestran una disposición favorable a un encuentro interreligioso que, pese a sus avances ${ }^{25}$, ve regularmente podridos sus frutos por manifestaciones extremistas y fundamentalistas. Pese al vaivén de avances y retrocesos, el potencial transformador de las religiones se expresa en dichos encuentros interreligiosos, que, si "fueran más coherentes y activamente practicados, podrían funcionar simultáneamente como una poderosa memoria y un campo de experimentación para diálogos más amplios, incluyendo concepciones religiosas y no-religiosas de dignidad humana" (De Sousa Santos, 2014, p. 120).

El encuentro interreligioso actualiza precisamente el asimétrico potencial liberador presente en todas las religiones que toman conciencia de su incidencia socio-política y sobrepasan el ámbito de lo privado, pues como agencias de la última dimensión existencial del ser humano son portadoras sempiternas de la esperanza y la salvación para toda la hu-

\footnotetext{
${ }^{25}$ Las religiones han celebrado varios encuentros desde que se reunieron por primera vez con carácter oficial, en Chicago (Estados Unidos), en 1893. Una cita en la que las espiritualidades y los credos minoritarios apenas estaban presentes ha ido evolucionando inclusivamente: casi un siglo después (en 1988) se formó el Consejo del Parlamento Mundial de las Religiones, que preparó el segundo encuentro mundial, nuevamente en Chicago, en 1993. Desde entonces, las reuniones interreligiosas se han sucedido: Ciudad del Cabo (Sudáfrica), en 1999; Barcelona (España), en 2004; Monterrey (México), en 2007; Melbourne (Australia), en 2009; Salt Lake City (Estados Unidos), en 2015; y Toronto (Canadá), en 2018.(Council for a Parliament of the World's Religions, 2019).
}

manidad, independientemente de las dificultades o imposibilidades que se encuentren en el camino.

Las religiones para la liberación se distinguen porque su horizonte sacral está atravesado por las víctimas, por la articulación existencial de las vidas que también merecen ser vividas, desde las que realizan una primera reflexión religiosa que conduce a su liberación fáctica. La relación primera es praxis-fe y no razón-fe. $Y$ es que, al habitar corporalmente las verdades, las víctimas son tanto el sujeto de acción de las religiones para la liberación (es decir, son las protagonistas de su reinterpretación hermenéutica del infinito) como su sujeto de estudio (es decir, las víctimas constituyen su preocupación central); no extraña por tanto que el lugar teológico de las religiones para la liberación, es decir, el locus enuntiationis a partir del cual se expresan, sean las víctimas.

A partir de estas premisas se abre un abanico irisado de religiones para la liberación ${ }^{26}$ : teología latinoamericana de la liberación, teología africana de la liberación, teología sudafricana negra de la liberación, teología asiática de la liberación, teología (eco)feminista ${ }^{27}$, teología de la liberación islámica, la religiosidad cósmica ${ }^{28} .$. "todas ellas constituyen la mejor expresión del (...) proceso de descolonización teológica en marcha" (Tamayo Acosta, 1993, pp. 1364-1365) y, articuladas en torno a la Asociación Ecuménica de Teólogos del Tercer Mundo (2019), estrechan lazos con frecuentes interpelaciones mu-

\footnotetext{
${ }^{26}$ La amplia amalgama de religiones para la liberación es estudiada por autores como Tamayo Acosta (2011) y Fornet-Betancourt (2006), separándose la propuesta de ambos, un encuentro interreligioso contextualizado y crítico, de la ética mundial de Küng.

27 "La teología feminista es una modalidad de teología crítica o de la liberación" (Forcades I Vila, 2011, p. 19).

28 "La religiosidad cósmica vivida por numerosas personas y comunidades populares en Asia posee también importantes aspectos liberadores. (...) Por eso (...) están siendo asumidos e integrados gradualmente (...) por las teologías de liberación" (Tamayo Acosta, 2004, p. 273).
} 
tuas desde su primer encuentro en Dar es Salam (Tanzania), en 1976. En ellas, la liberación no constituye una nueva temática teológica ${ }^{29}$, sino el horizonte de un paradigma en torno a las víctimas que abordan desde una actitud ético-política antes que noética y en el que la justicia "es el momento de mayor densidad de la fe. Pero no solo eso. Constituye, asimismo, un momento interno del conocimiento religioso" (Tamayo Acosta, 1993, p. 1371).

Por encima de sus respectivas peculiaridades, comparten una serie de rasgos formales: son religiones jóvenes, dinámicas y creativas, surgidas desde el sur global, entre dictaduras y condiciones infrahumanas: "Son, por tanto, teologías elaboradas en y desde la periferia, ubicadas en el reverso de la historia, donde la pobreza constituye un fenómeno masivo y estructural. $Y$ este origen define su punto de partida (...) y (...) el tipo de preguntas a las que intentan responder, (...) también el principal desafío al que se enfrentan" (Tamayo Acosta, 1993, pp. 1365-1366). Esta ubicación, explicitada abiertamente en sus postulados, las sitúa como teologías glocales: parten de las injusticias locales y aspiran a liberaciones globales. A pesar de esta procedencia, hay que señalar que el proceso de gestación no fue completamente independiente del Norte, "ya que la mayoría de los teólogos que han encabezado esta corriente han estudiado en las confortables universidades europeas" (Sols, 1994/1992, p. 23).

Están orientadas o sureadas críticamente con respecto a la teología moderna del centro, a la que denuncian como supraestructura de dominación de pretensiones universalistas: "La Iglesia, como institución y realidad histórica, ha tenido una presencia muy ambigua en el proceso de liberación. Especialmente en América Latina, (...) ha sido estructuralmente (...) compañera de la dominación y cómplice de los mecanismos de opresión"

\footnotetext{
${ }^{29}$ Literalmente son más teologías para la liberación que teologías de la liberación. No son teologías de genitivo.
}

(Boff, 1981, p. 130). Sí mantienen afinidad con las teologías políticas europeas, con las que asumen "la afirmación de que toda teología está impregnada por lo político" (Sols, 1994/1992, p. 22), entendiendo la política en su sentido transformador, es decir, como praxis, como la práctica colectiva de relacionarse públicamente entre sí los seres humanos finitos e interdependientes: "Cuando la teología de la liberación habla de compromiso político se está refiriendo a la política entendida como una participación en la construcción de la sociedad (...). Se toma, por tanto, la política y su aceptación más honda y noble. (...) En este sentido, hay que distinguir muy bien entre compromiso político de la Iglesia y politización de la misma" (García Añoveros, 1989, p. 195).

Además, comparten con las teologías políticas europeas el afán por desprivatizar la fe $y$, metodológicamente, el impulso práctico enunciado por Marx en la tesis 11 sobre Feuerbach ${ }^{30}$ : defienden que la teología sucede a o es un a posteriori de dicha praxis, en particular, la que arranca en la realidad histórica de las periferias, analizada a través de las ciencias sociales bajo un prisma dialécticoestructural ${ }^{31}$ : "La praxis liberadora no es ni pura actividad ni pura teoría. Es acción reflexionada por reflexión activada. Supera la dicotomía: acción por un lado; teoría, por otro. Se trata de una acción-reflexión transformante. El hombre pasa así de ser coespectador a actor de su liberación. Ni verbalismo ni activismo. Es un hacer pensando y un pensar haciendo sobre las estructuras que oprimen al hombre" (García Añoveros, 1989, p. 172).

\footnotetext{
30 "Los filósofos [en este caso, las religiones] no han hecho más que interpretar de diversos modos el mundo, pero de lo que se trata es de transformarlo" (Marx, n.d).

${ }^{31}$ Frente al análisis social funcionalista, que comprende la sociedad como un todo orgánico, la visión dialéctica "atiende más a los conflictos y desequilibrios que afectan al sector de los depauperados, y exige una reformulación del sistema social, de forma que manifieste una mayor simetría y una mayor justicia para todos" (Boff, 1981, p. 76).
} 


\section{La teología latinoamericana de la liberación}

La teología latinoamericana de la liberación ${ }^{32}$ es el marco de referencia de todas ellas, por ser la que más recorrido y alcance ha cosechado y porque supuso la primera $^{33}$ concreción organizada de las mismas. Surge en la década de los años 60 en Nuestra América, con especial incidencia en Brasil, y en el seno del cristianismo, tanto de pensadores católicos (Dussel, los hermanos Boff, Gutiérrez, Segundo, Comblin, Assmann) como protestantes (Alves, Bonino, Shaull), apareciendo oficialmente durante el Concilio Vaticano II (19621965) y en la posterior reunión de los obispos latinoamericanos en la Conferencia de Medellín (1968). Muy pronto comienza a girar en torno a las comunidades de base, articuladas por las propias víctimas, hasta entonces excluidas del paradigma eclesial del Norte ${ }^{34}$.

Su emersión concreta tiene lugar ante la preocupación por una situación antropológica intolerable que la religiosidad silencia o al menos contra la cual no brama: la dependencia que vive la población empobrecida de América del Sur. "La teología se había quedado sin historia. La teología de la liberación se hace historia. Cae una determinada metafísica de esencias inmutables y externas (...). Se abandona una concepción del hombre flotando en

\footnotetext{
${ }^{32} \mathrm{Al}$ igual que sucedía con las filosofías de la liberación latinoamericana, la enunciación en singular de la teología latinoamericana de la liberación no debe ocultar su diversidad interna, presente ya desde el inicio. En este caso, un análisis más detallado excede los límites de este artículo filosófico. Al respecto, puede consultarse (Cerutti Guldberg, 2006 ; (Dussel Ambrosini, 1992).

${ }^{33}$ En estricto orden cronológico, la sistematización de la teología latinoamericana de la liberación coincide con la de la teología negra de la liberación surgida en Estados Unidos (Cone, 2017).

${ }^{34}$ La opción por las víctimas no había tenido prácticamente eco hasta entonces en los documentos conciliares y todavía en la actualidad es asumida con reservas por la cristiandad institucional, pese a que la llegada del papa Francisco en 2013 supuso un espaldarazo al proceso.
}

la pura abstracción y se encuentra con el hombre real e histórico. (...) Parte de una visión antropológica en la que el hombre es fundamentalmente relación y dinamismo histórico y no una sustancia cerrada y acabada" (Garcia Añoveros, 1989, p. 172).

Esta preocupación antropológica no es un hecho aislado, sino que forma parte de la irrupción de las periferias en la escena histórica, a través de los movimientos populares revolucionarios de liberación extendidos por la geografía suramericana. Pero su fe liberadora no se disuelve en el proceso revolucionario, sino que se transforma para conjugarse como fuerza de liberación y hacer así realidad los valores del credo cristiano. Las reflexiones críticas en torno al contexto de subdesarrollo "permitieron a los cristianos comprometidos comprender que las instancias económica, política y social son algo más: son lugares en los que se hacen historia la Gracia y el pecado, la opresión y la liberación. Lo cual quiere decir que lo económico, por ejemplo, es algo más que económico; es teologal y sacramental, porque es vehículo de una realidad de salvación o de perdición" (Boff, 1981, p. 70).

La teología latinoamericana de la liberación enarbola 'su liberación' en tres sentidos: liberación política frente al proceso de desarrollo del sistema hegemónico, liberación del ser humano a través de la historia (asunción consciente del propio destino) y liberación del pecado (la comunión aportada por (risto). Bajo este haz liberador, reformula conceptos y posturas de fe trasversales para toda teología ('dios', 'salvación', 'comunidad', 'fe'), sin perder nunca de vista el contexto suramericano y admitiendo sus filias y sus fobias políticas: como teología situada a partir de los pobres, remarca su pertenencia a la familia de las teologías políticas, principalmente vía Metz (1979) y Moltmann (ver 2006), de quienes se nutre pero de quienes se distancia paulatinamente ${ }^{35}$.

\footnotetext{
${ }^{35}$ Dussel Ambrosini (1974) analiza críticamente el aporte de ambos autores en relación con la teología latinoamericana de la liberación: "Moltmann,
} 
Sustituye la mística de la austeridad obligada por el compromiso responsable por y con los pobres, la protesta y la lucha contra la pobreza. En definitiva, toma partido por los pobres, entendiendo que la pobreza no es un camino hacia dios, sino un mal a erradicar, lo que le sitúa en una posición comprometida que acaba incluso en el asesinato: "Por defender al pobre ha entrado en grave conflicto con los poderosos de las oligarquías económicas y los poderes políticos y militares del Estado" (Romero, 1980, p. 113) ${ }^{36}$.

Más que la apuesta por un modelo político en concreto, la teología latinoamericana de la liberación opta por la ruptura con el capitalismo: "Había una experiencia real del capitalismo y de sus males y no había una experiencia real del socialismo y sus males. Esto hace que la teología de la liberación, en vez de pretender y propiciar una reforma del capitalismo, se esfuerce en conseguir una reforma del socialismo. (...) Se pasa así de una posición anticapitalista a una posición prosocialista. Lo primerio es la posición anticapitalista" (Ellacuría Beascoechea, 1989, p. 82). Equivocadamente se la identifica con el marxismo, cuando en realidad es empleada críticamente como mediación socio-analítica de la sociedad: "La teología de la liberación no depende del marxismo como su inspiración principal. (...) Tiene, por el contrario, la capacidad de revitalizarlo" (Dussel Am-

aunque plantea la cuestión de la planificación de un proyecto futuro, no toca el fenómeno del proyecto histórico de liberación, que incluye todo un compromiso económico, político, cultural. Y al no hacer eso, (...) desencarna la esperanza, o aun la transforma en opio. (...) De igual manera, (...) Metz dice, y con razón, que la teología tradicional ha sido un pensar privatizado, del individuo que cumplía su función dentro de la Iglesia y en la sociedad sin sentido crítico. La teología era cómplice, entonces, del sistema. (...) Pero esa crítica se efectúa desde el horizonte de una nación, y mucho más en concreto, de una nación europea. (...) El punto de apoyo de su crítica es el 'centro', que es muy distinto que si uno se encuentra en 'la periferia'" (pp. 178 y 179).

36 Palabras premonitorias, Romero fue asesinado un día después de haber exigido, durante su homilía del 23 de marzo de 1980, el fin de la represión salvadoreña. brosini, 1992, p. 413). Su opción preferencial por los pobres concuerda con la existencia de clases sociales, "pero su opción no se agota en esta clase, pues abarca más que la clase pobre. Desde los pobres se dirige a otras clases, matizando su discurso. (...) Esto (...) significa que, una vez alcanzados por el anuncio evangélico, los ricos deben sentirse urgidos a comprometerse por la justicia y en contra de la pobrezainjusticia y la explotación" (Boff, 1981, p. 199).

Ya superado el medio siglo desde su presentación al mundo, Dussel Ambrosini $(1992 ; 2003)$ distingue hasta cinco etapas evolutivas. De un primer período de incubación (1959-1968), impregnado por los procesos revolucionarios en liza, se pasa a un segundo momento creativo (1968-1972), en el que comienza a forjarse un corpus propio e independiente de las teologías políticas europeas ${ }^{37}$. La crítica y la persecución a los teólogos de la liberación se recrudece en la tercera fase (19721984), que incluye el asesinato de monseñor Romero y finaliza con el juicio y excomunión de Leonardo Boff ante la Doctrina de la Fe. La caída del muro de Berlín y la crisis del socialismo real abrieron una cuarta etapa (1989-2000) cargada de incertidumbre respecto al futuro de la teología de la liberación, cuyos postulados se dieron por desfasados ante el fracaso empírico del marxismo.

Su vigencia actual (desde el 2000) continúa entre críticas tanto internas como externas. Como principal metamorfosis, la opción preferencial por los empo-

\footnotetext{
37 Los debates internos fueron intensos en esta segunda fase. Entre otros, se plantea "si se subraya la liberación de la teología (Segundo) o si se subrayaba la teología de la liberación (Gutiérrez). En el primer caso, lo que se pretende más inmediatamente es que la fe y la teología se liberen en lo que ellas mismas han tenido de contribución ideológica y social a que la región y/o fe cristiana hayan sido parte de la opresión. (...) En el segundo caso, lo que se pretende más inmediatamente es utilizar la fuerza social de la ley de la Iglesia en la liberación sociohistórica de los pueblos" (Ellacuría Beascoechea, 1989, p. 69).
} 
brecidos ha dado paso a la opción preferencial por las víctimas: "El pobre es una realidad. (...) Es también la 'metáfora' de todos los oprimidos. Pero, como metáfora, no podía ser aceptada por 'otros' humillados o negados. (...) Ha comenzado a usarse, con mucho sentido, la palabra 'víctima'. Menos económica, pero no por ello menos material y crítica. (...) Sin comunidad de víctimas, las Iglesias están vacías de contenidos" (Dussel Ambrosini, 2003, p. 296). No es solo una cuestión lingüística $y$, de hecho, su trascendencia rebasa la liberación 'erótica' que plantea Dussel desde el eros, esfera del amor que no abarca la complejidad y profundidad de la imposición de género (Vuola, 2000).

\section{A modo de crítica conclusiva}

Precisamente desde las teologías (eco)feministas llegan renovados cuestionamientos a estas teologías de la liberación, comenzando por la ausencia de sujetos alterativos en la liberación religiosa, concretamente, la naturaleza (por el antropocentrismo aún presente) y las mujeres (por el androcentrismo ${ }^{38}$ ), lo que impide incluir planteamientos religiosos transformadores como el de la corporeidad: " $E I$ cuerpo femenino (...) es un camino poderosamente iluminador e inspirador para la teología sacramental (...), dado que presenta nuevos paradigmas más allá de las siempre presentes cuestiones de género. (...) Este hecho simbólico y teológico de los cuerpos de las mujeres no permanece solo en el ámbito personal, sino que también tiene implicaciones comunitarias y políticas" (Lucchetti Bingemer, 2018, p. 22). Hay que sumar las sospechas discursiva y lingüística: la expresión teológica es eminen-

\footnotetext{
38 "En sus inicios, la teología de la liberación concedió poca relevancia - por no decir ninguna- a la perspectiva de la mujer. (...) Se hablaba, es verdad, de la liberación integral, pero en abstracto, sin apenas referencia a los fenómenos de marginación de género. (...) Las mujeres (...) fueron las grandes olvidadas del nuevo pensamiento teológico liberador" (Tamayo Acosta, 2011, p. 254).
}

temente heteropatriarcal, al igual que lo son las prácticas al interior de las Iglesias y de las diversas instituciones religiosas ${ }^{39}$.

$Y$ existe el riesgo de que el llamado al 'dios de los pobres' (versus el dios de los ricos) se quede en una invocación provocativa que no transforme el paradigma existencial de lo religioso: "El carácter fundamentalmente antropocéntrico y androcéntrico de la teología de la liberación es indiscutible. Se trata de Dios en la historia de los hombres, un dios que finalmente continúa siendo el Creador y el Señor. (...) No se siente la necesidad de rever las bases cosmológicas y antropológicas de la formulación de la fe. (...) La distancia, la discontinuidad entre la vida de Dios y la vida humana continúan siendo acentuadas" (Gebara, 2000, pp. 67-68). En definitiva, las teologías feministas de la liberación Ilaman la atención sobre el encubrimiento de las problemáticas de género, culturales y étnico-raciales que puede conllevar una opción eclesial exclusivamente de clase.

La teología latinoamericana de la liberación ha ido abriéndose paulatinamente al resto de teologías de la liberación y hoy puede hablarse de una metateología de las diversas teologías de la liberación. "Es necesario (...) comprender que en cada una de estas teologías de la liberación específica se encuentran en planos de profundidad todas las otras. [La metateología de la liberación] deberá aprender el ejercicio de una razón teológica 'transversal'"' (Dussel Ambrosini, 2003, p. 297). En lo sucesivo, habrá que ver si esta metateología cumple con las respectivas liberaciones por las que aboga, cómo, en qué medida y en función de qué renuncias o posiciones. Es la hora por ejemplo de cerrar interrogantes abiertos, como el de su aplicabilidad transformadora en los sures del Norte.

\footnotetext{
39 "El poder eclesiástico sobre lo religioso excluiría casi inmediatamente cualquier intento de 'intromisión' que pretenda cambios significativos. Basta ver la ausencia flagrante de mujeres en los procesos de decisión, en las instancias de poder de las diferentes Iglesias" (Gebara, 2003, p. 323).
} 
Además, la teología de la liberación latinoamericana justifica su discurso sobre Dios (al que se resiste a presentar debilitado o vaciado) apelando a la praxis liberadora de los creyentes, en un planteamiento en el que no aborda la negación atea ni la duda agnóstica entre lo otro infinito y la nada infinita. Se le debe pedir además que su traducción del mesianismo bíblico y su fuerza transgresora en una praxis histórica de liberación no caiga en ingenuos mesianismos políticos; y que no sea ambigua a la hora de definirse entre ciertas formas de populismo. Igualmente es cuestionable su postura con respecto a los movimientos de liberación, pudiéndola incluso acusar de sacralizar a alguno de ellos sin la debida distancia crítica. También se echa en falta una reflexión más profunda acerca de la violencia.
Y, no menos importante, está en juego el equilibro liberador entre las distintas dimensiones existenciales de la humanidad: "Se suele acusar a la teología de la liberación de que convierte a la Liberación en un proyecto de la historia presente construida por los hombres. Se pone tal énfasis en el ahora de la historia que no queda lugar para el futuro de Dios" (García Añoveros, 1989, p. 189). Siempre con las víctimas en el horizonte, la filosofía de la religión tiene el reto de ser uno de los campos de pensamiento desde los que se aborden todas estas interrogantes con mayor lucidez.

\section{Referencias Bibliográficas}

Asociación Ecuménica de Teólogos /as del Tercer Mundo. (2019). “Comisión Teológica Latinoamericana". Recuperado de https://www.eatwot.net/

Boff, L. (1981). La fe en la periferia del mundo. (J. García-Abril, Trad.). Bilbao: Sal TerraeKairós.

Cantor, G. (2006). Fundamentos para una teoría general de conjuntos: escritos y correspondencia selecta. (J. Ferreiros \& E. Gómez-Caminero, Trads.). Barcelona: Crítica.

Cerutti Guldberg, H. (2006). Filosofía de la liberación latinoamericana (3a ed.). México, DF: Fondo de Cultura Económica.

Cone, J. (2017). A black theology of liberation. New York, NY: Orbis.

Council for a Parliament of the World's Religions. (2019). Parliament of the world's religions. Recuperado de https://parliamentofreligions.org/

De Sousa Santos, B. (2005). El milenio huérfano: ensayos para una nueva cultura política. (A. Barreto, Trad.). Madrid: Trotta.

De Sousa Santos, B.(2014). Se deus fosse um ativista dos direitos humanos. Coimbra: Almedina.

Dussel Ambrosini, E. (1974). Caminos de liberación latinoamericana Il: teología de la liberación y ética. Buenos Aires: Latinoamérica Libros. Recuperado de https://bit.ly/34Uhx2e 
Dussel Ambrosini, E. (1992). Historia de la Iglesia en América Latina: medio milenio de coloniaje y liberación (1492-1992) (6 $6^{a}$ ed.). Madrid: Mundo Negro. Recuperado de https://bit.ly/2EU98kM

Dussel Ambrosini, E. (2001). Hacia una filosofía política crítica. Bilbao: Desclée de Brouwer. Recuperado de https://bit.ly/2MtLz6u

Dussel Ambrosini, E. (2003). Transformaciones de los supuestos epistemológicos de la teología de la liberación. En R. Fornet Betancourt (Ed.), Resistencia y solidaridad: globalización capitalista y liberación (pp. 291-299). Madrid: Trotta.

Ellacuría Beascoechea, I. (1989). La Teología de la Liberación frente al cambio sociohistórico de América Latina. En su Implicaciones sociales y políticas de la teología de la liberación (pp. 69-90). Sevilla: Escuela de Estudios Hispanoamericanos.

Forcades I Vila, T. (2011). La teología feminista en la historia. (J. Argemí, Trad.). Barcelona: Fragmenta .

Fornet-Betancourt, R. (2006). La interculturalidad a prueba. Aachen: Mainz.

Fraijó Nieto, M. (2005). Filosofía de la religión: estudios y textos (3a ed.). Madrid: Trotta.

Fraijó Nieto, M. (2006). Dios, el mal y otros ensayos. Madrid: Trotta.

Fraijó Nieto, M. (2007). A vueltas con la religión (3a ed.). Pamplona: Verbo Divino.

García Añoveros, J. (1989). Puntos conflictivos de la Teología de la Liberación. En I. Ellacuría Beascoechea (Ed.), Implicaciones sociales y políticas de la teología de la liberación (pp. 165202). Sevilla: Escuela de Estudios Hispanoamericanos.

Gebara, I. (2000). Intuiciones ecofeministas: ensayo para repensar el conocimiento y la religión. (G. Pujol, Trad.). Madrid: Trotta.

Gebara, I. (2003). Nuevas vías para la transformación de la estructura de la teología. Una propuesta de la teología feminista latinoamericana. En R. Fornet-Betancourt (Ed.). Resistencia y solidaridad: globalización capitalista y liberación (pp. 319-333). Madrid: Trotta.

Heidegger, M. (1994). Conferencias y artículos. (E. Barjau, Trad.). Barcelona: Ediciones del Serbal.

Horkheimer, M. (2000). Anhelo de justicia. Teoría crítica y religión. (J. Sánchez, Trad.). Madrid: Trotta.

Huntington, S. (2001). El choque de civilizaciones y la reconfiguración del orden mundial. (J. Tosaus Abadía, Trad.). Barcelona: Paidós Ibérica.

Küng, H. (1979). ¿Existe Dios? Respuesta al problema de Dios en nuestro tiempo. (J. Bravo Navalpotro, Trad.). Madrid: Cristiandad. 
Küng, H. (1998). Teología para la postmodernidad: fundamentación ecuménica. (G. Canal, Trad.). Madrid: Alianza.

Küng, H. (1999). Una ética mundial para la economía y la política. (G. Canal, Trad.). Valladolid: Trotta.

Küng, H. (2006). Proyecto de una ética mundial. (G. Canal, Trad.) (7a ed.). Madrid: Trotta.

Lucchetti Bingemer, M. (2018). Transformar la Iglesia y la sociedad en femenino. Cuadernos cristianisme i justícia, (211), 1-32. Recuperado de https://bit.ly/2PV9xcW

Marx, K. (s. d.). Tesis sobre Feuerbach. Recuperado de https://bit.ly/2MxJnei

Melloni Ribas, J. (2000). Los ciegos y el elefante: el diálogo interreligioso. Cuadernos cristianisme i justícia, (97). 1-24. Recuperado de https://bit.ly/2rsBWh0

Metz, J. (1979). La fe, en la historia y la sociedad: esbozo de una teología política fundamental para nuestro tiempo. (M. Olasagasti y J. Bravo, Trads.). Madrid: Cristiandad.

Metz, J. (2007). Memoria passionis: una evocación provocadora en una sociedad pluralista. (J. Lozano, Trad.). Santander: Sal Terrae.

Moltmann, J. (2006). Teología de la esperanza. (A. Sánchez Pascual, Trad.) (7a ed.). Salamanca: Sígueme.

Muguerza Carpintier, J. (2006). Desde la perplejidad: ensayos sobre la ética, la razón y el diálogo (4a ed.). Madrid: Fondo de Cultura Económica.

Nietzsche, F. (2003). Así habló Zaratustra. (A. Sánchez Pascual, Trad.). Madrid: Alianza.

Panikkar, R. (1965). Religión y religiones. Madrid: Gredos.

Pew Research Center. (2019). Pew-Templeton: Global Religious Futures Project. Recuperado de http://globalreligiousfutures.org/

Romero, Ó. (1980). La dimensión política de la fe desde la opción por los pobres. En su ¡Cese la represión! (pp. 109-119). Madrid: IEPALA.

Scannone, J. (2005). Religión y nuevo pensamiento: hacia una filosofía de la religión para nuestro tiempo desde América Latina. Barcelona: Anthropos.

Sobrino, J. (1988). Religiones orientales y liberación. Cuadernos cristianisme i justícia, (25). 114. Recuperado de https://bit.ly/2Mt3f1Y

Sobrino, J. (2007). Fuera de los pobres no hay salvación. Pequeños ensayos utópico-proféticos. Madrid: Trotta.

Sols Lucia, J. (1994). Teología de la marginación. Cuadernos cristianisme i justícia, (46). 19-25. Recuperado de https://bit.ly/2EQE0md 
Tamayo Acosta, J. (2003). Hacia una teología liberadora desde la exclusión en tiempos de globalización. En R. Fornet-Betancourt (Ed.). Resistencia y solidaridad: globalización capitalista y liberación (pp. 385-396). Madrid: Trotta.

Tamayo Acosta, J. (2004). Fundamentalismos y diálogo entre religiones. Madrid: Trotta.

Tamayo Acosta, J. (2011). Otra teología es posible: pluralismo religioso, interculturalidad y feminismo. Barcelona: Herder.

Tamayo Acosta, J. (1993). Teologías de la liberación. En J. Tamayo Acosta y C. Floristán (Eds.). Conceptos fundamentales del cristianismo (pp. 1363-1376). Madrid: Trotta.

Tatay Nieto, J. (2019). Creer en la sostenibilidad: las religiones ante el reto medioambiental. Cuadernos cristianisme i justícia, (212). 1-30. Recuperado de https://bit.ly/2ruaHCR

Tatay Nieto, J. y Devitt, C. (2017). Sustainability and interreligious dialogue. Islamochristiana, (43). 123-139. Recuperado de https://bit.ly/2Sp3Gyd.

Vattimo, G. (1996). Creer que se cree. (Carmen Revilla, Trad.). Barcelona: Paidós.

Vattimo, G. (2003). Después de la cristiandad: por un cristianismo no religioso. (Carmen Revilla, Trad.). Barcelona: Paidós.

Vattimo, G. (2010). Adiós a la verdad. (M. D'Meza Pérez, Trad.). Barcelona: Gedisa.

Vattimo, G. y Caputo, J. (2010). Después de la muerte de Dios: conversaciones sobre religión, política y cultura. (A. Antón Trad.). Barcelona: Paidós.

Vuola, E. (2000). Teología feminista: teología de la liberación. (J. Solá de Guerrero, Trad.). Madrid: IEPALA.

\section{Para citar este artículo bajo Norma APA 6a ed.}

Marcos, J. (2019). Más acá de la divinidad absoluta.

Cuadernos de Teología - Universidad Católica del Norte

(En línea), 11, e3777, https://doi.org/10.22199/issn.

0719-8175-2019-0004

DOI

Copyright del articulo: @2019 Jairo Marcos

Este es un artículo de acceso abierto, bajo licencia Creative Commons BY 4.0 